\title{
Metisilin Dirençli Staphylococcus aureus ve Önemi
}

\author{
Barışhan Doğan ${ }^{1}$, Mücahit Palaz ${ }^{1}$, Müjgan İzgür ${ }^{1}$ \\ ${ }^{1}$ Ankara Üniversitesi Veteriner Fakültesi, Mikrobiyoloji Anabilim Dall, Ankara, Türkiye
}

Geliş Tarihi / Received: 03.05.2018, Kabul Tarihi / Accepted: 06.07.2018

\begin{abstract}
Özet: Metisilin Dirençli Staphylococcus aureus (MRSA), antimikrobiyallere karşı geliştirdiği direnç mekanizmaları sayesinde dikkatleri üzerine çekerek günümüzde çok önemli bir konuma sahip olmuştur. Stafilokoklar, insanlarda ve hayvanlarda normal mikrobiyota etkeni olarak bulunmasının yanı sıra patojen, humanoz, zoonoz karakterli enfeksiyonlar başta olmak üzere lokal ve sistemik enfeksiyonlara neden olan piyojenik karakterli etkenlerdir. Hazırlanan bu derleme ile MRSA'nın önemine dikkat çekmek, bilinçli antibiyotik kullanımına vurgu yapmak amaçlanmıştır.
\end{abstract}

Anahtar kelimeler: MRSA, Metisilin direnci, Stapylococcus aureus.

\section{Methicillin Resistant Staphylococcus aureus and Importance}

\begin{abstract}
Methicillin Resistant Staphylococcus aureus (MRSA) has a very important position today by drawing attention to its resistance mechanisms developed against antimicrobials. Staphylococci have a pyogenic character that causes local and systemic infections, particularly pathogenic, humanotic, zoonotic infections, as well as normal microbiota effects in humans and animals. With this review, it is aimed to draw attention to the importance of MRSA and to emphasize the use of conscious antibiotics.
\end{abstract}

Key words: MRSA, Methicillin resistance, Staphylococcus aureus.

\section{Giriş}

Staphylococcus aureus'lar ölümcül tehlikeye sahip mikroorganizmalar olarak geçtiğimiz yüzyıl boyunca tıbbi bilimler alanında oldukça önemli yer bulmuştur. Stafilokoklar ilk kez 1881 y1lında İskoçya'lı cerrah ve bakteriyolog Alexander Ogston tarafindan tanımlanmıştır. Etkenin o dönemde çok ağır klinik tabloyla seyreden, tedavisi oldukça zor, ölümcül karakterde enfeksiyonlara neden olduğu bilinmektedir [35]. S. aureus'larda bildirilen ilk antibiyotik direnci 1920'li yılların sonuna doğru yaygın klinik kullanıma giren sülfonamid grubu antibiyotiklerle başlamıştır. 1928 yılında Alexander Fleming'in penisilini bulmasından sonra 1940 yılında Forey ve Chain tarafından penisilinin üretiminin başarılması ile stafilokokal enfeksiyonların tedavisinde önemli bir aşama kaydedilmiştir [8]. Ancak penisilinin yaygın bir şekilde klinik kullanıma girmesiyle birlikte yaklaşık dört yıl içerisinde penisiline dirençli (beta-laktamaz enzimi sentezleyen) S. aureus suşlar1nın varlığı açıklanmıştır. Stafilokoklarda beta-laktamaz (penisilinaz) sentezlenmesi ilk olarak 1944'te Kirby tarafindan bildirilmiştir. Bu tarihten itibaren $S$. aureus suşlarında penisilin direnci giderek art- mış, 1951 yılında çoklu dirençli $S$. aureus suşlarının varlığı bildirilmiştir [30].

Penisiline karşı oluşan direnç problemine 1959 yılında beta-laktamaz enzimine dayanıkl1, semisentetik (yar1 sentetik) bir penisilin olan metisilin ile çözüm bulunmuştur [41]. 1960 y1lında metisilinin ve daha sonra da penisilinaza (beta-laktamaz) dirençli diğer penisilinlerin kullanıma girmesiyle birlikte stafilokokal enfeksiyonların tedavisinde önemli başarılar elde edilmiştir. Metisilinin çok yaygın ve özensiz kullanımı ile bulunan bu çözüm de uzun sürmemiş, kısa bir süre sonra $S C C m e c$ ( $S C C$, Staphylococcal Casette Chromosome; mec, metisilin direncine neden olan genetik eleman) klonlarının kazanılmasıyla $S$. aureus suşlarında çoklu antibiyotik direnç problemi ortaya çıkmıştır. İlk olarak 1961 yılında İngiltere'de Jevons tarafindan metisilin dirençli Staphylococcus aureus (MRSA) izolatları tanımlanmıştır [24].

MRSA'da direnç probleminin artması ile birlikte dünya genelinde başta nozokomiyal yani hastane kaynaklı enfeksiyonlar (HA-MRSA-Hospital Acquired MRSA) olmak üzere, toplumsal kaynaklı (CA-MRSA-Community Acquired MRSA) ve hay- 
vansal kaynaklı (LA-MRSA-Livestock Acquired MRSA) enfeksiyonlara neden olduğu bilinmektedir. HA-MRSA yüksek mortalite ile seyreden enfeksiyonların en önemli nedenleri arasında gösterilmektedir $[9,33]$.

Günümüzde MRSA enfeksiyonlarının tedavisinde en çok kullanılan antibiyotikler ise vankomisin ve teikoplanindir. Bunların yanı sıra linezolid, daptomisin ve tigesiklin gibi yeni antibiyotikler de kullanılmaya başlamıştır. Buna rağmen stafilokoklarda görülen hızlı direnç gelişimi her iki yeni antibiyotiğe karşı da ortaya çıkmıştır. 1996 yılında VISA (Vancomycin Intermediate $S$. aureus) izolatlar1 ve 2002 yilinda da VRSA (Vancomycin Resistant $S$. aureus ) izolatları görülmeye başlanmıştır. Linezolid ilk kez 2000 yılında klinik kullanıma girmiş ve bundan yaklaşık bir yıl gibi çok kısa bir süre sonra ilk linezolid dirençli MRSA izolatı tanımlanmıştır. Daha sonra benzer bir şekilde, daptomisin ilk kez 2003 yılında klinik kullanıma girmiş ve kullanıma girdikten iki yıl sonra daptomisin dirençli MRSA izolatları tanımlanmıştır [43].

\section{Stafilokoklarda Metisilin Direnç Mekanizmaları}

Metisilin, beta-laktamaz enziminin hidrolizine dirençli penisilin grubu antibiyotikler içerisinde ilk elde edilen ve klinik kullanıma ilk giren antibiyotiktir [24]. Metisilin direnci, beta-laktamaz enzimiyle hidrolize olmayan beta-laktam antibiyotiklere (metisilin, oksasilin, kloksasilin, dikloksasilin) karşı gözlemlenen direnç olarak adlandırılır. Metisilin direnci, aynı zamanda intrinsik direnç yoluyla yani antibiyotiği inaktive eden faktörün beta-laktamaz enzimiyle değil, kromozomal yolla meydana geldiği bilinir [6].

S. aureus'ta metisilin direnci, penisilinaz (beta-laktamaz) üretiminden farklı bir mekanizma olan "Penisilin Bağlayan Protein" (PBP)'ler ile gerçekleşmektedir. PBP'ler, peptidoglikan öncüllerini yapılmakta olan hücre duvarına taşımak ve bağlamakla görevlidir. Metisiline duyarlı $S$. aureus (MSSA)'larda, beş adet 'Penisilin Bağlayan Protein" (PBP) bulunurken, MRSA'larda bunlara ek olarak PBP2 ya da PBP2a olarak adlandirilan 78 $\mathrm{kDa}$ ağırlıkta olan farklı bir PBP sentezlenmektedir [16]. PBP2/2a, diğer PBP'lerden farklı olarak beta-laktam yapısındaki antibiyotiklere karșı düșük affinite göstermektedir. Dolayısıyla, beta-laktam grubu antibiyotik varlığında, yüksek affinite gösteren PBP'lerin fonksiyonunu görerek peptidoglikan sentezini sürdürebilme yeteneğine sahip olan tek transpeptidazdir [14, 25].

Duyarl1 stafilokok izolatlarında beta-laktamlar, duvar prekürsörleri ile yarışarak enzimin aktif bölgesine bağlanıp, bu transpeptidasyon basamağ1$\mathrm{n} 1$ inhibe ederler. Ancak, doğal prekürsörden farklı olarak, bu bağlanmanın geriye dönüşlü olmaması nedeni ile PBP aktivitesi kalıcı olarak bloke edilir ve bakteriyel ölüm gerçekleşir. Bakteri duvarındaki peptidoglikanın çapraz bağlanmasını sağlayan diğer PBP'ler beta-laktamlar varlığında inaktive olurken, PBP2/2a beta-laktamlara karşı düşük affiniteye sahip olduğundan, inaktive olmuş PBP'lerin yerine geçer ve varlığında hücre duvarı peptidoglikan sentezi tamamlanır $[14,25]$. Bu proteinlerin bir kısmı iki fonksiyonlu olup hem transglikosidaz hem de transpeptidaz aktivitesine sahiptir [20]. S. aureus, bir adet iki fonksiyonlu PBP2 ve tek fonksiyonlu PBP1, PBP3 ve PBP4 olmak üzere üç adet PBP'ye sahiptir [25]. MRSA'da temel direnç mekanizması, beta-laktam grubu antibiyotiklere karşı düşük affiniteye sahip yeni bir penisilin bağlayan protein olan PBP2/2a sentezine dayanmaktadır [6, 29].

PBP'leri mecA ve mecC olarak adlandirılan genler kodlamaktadır ve bu genler bakteri kromozomunda SCCmec kasetleri üzerinde yer almaktadır. MRSA'lar bu gene sahipken MSSA'larda bu gen bulunmamaktadır. SCCmec kasetlerinin büyüklükleri 20 kb'dan 68 kb'a kadar değişkenlik gösteren 11 tipi (Tip I-XI) bulunmaktadır[1, 2, 39]. Tip I, IV ve $\mathrm{V}$, sadece yapısal ve regülatör genler ile rekombinaz genlerini içerir. $\mathrm{Bu}$ alt tiplerde, transpozon elemanları ve beta-laktam antibiyotik dışındaki antibiyotiklere dirençten sorumlu olan genler bulunmamaktadır. HA-MRSA'lar SCCmec kasetleri üzerinde alt tip I, II ve III'ü içerirken, CA-MRSA'lar SCCmec kasetleri üzerinde alt tip IV ve V'i içermektedir $[1,2,20]$.

MRSA'larda mecA geninin varlığ çıkan bu direnç, fenotipik laboratuvar testlerinde homojen direnç ve heterojen direnç olmak üzere iki şekilde ortaya çıkmaktadır. Homojen direnç, koloniyi oluşturan tüm $S$. aureus'ların mecA genine sahip olmas1 ve tamamında da bu genin aktif olması durumudur. Oluşan yüksek direncin çevresel faktörlerle ilişkisi bulunmamaktadır [36]. mecA 
geninin tamamında aktif olması durumunda ortaya çıkan fenotipik direnç yüksek düzeydedir. Homojen dirençte bakterilerin tamamı yüksek konsantrasyondaki metisilin varlığında üreyebilme özelliği göstererek yüksek düzeyde direnç ortaya koyarlar [6, 18]. MRSA'larda görülen bu yüksek direnç yakın geçmişe kadar nadiren görülmekteyken günümüzde oldukça fazla rastlanmaktadır. Heterojen direnç, koloniyi oluşturan tüm $S$. aureus suşlarının mecA genini taşımalarına rağmen yüksek direncin $10^{6}-10^{8}$ bakteriden birinde belirlenebilmesi olarak tanımlanmaktadır ve izolasyon uygulamaları sirasında en sık karşılaşılan direnç şeklidir [19, 20]. Heterojen direnç gösteren MRSA'larda, stafilokokların çoğunluğu (\%99) düşük metisilin konsantrasyonlarına $(1-5 \mu \mathrm{g} / \mathrm{mL})$ duyarlı iken, $10^{2}-10^{8}$ stafilokoktan biri yüksek metisilin konsantrasyonlarına ( $\geq 50 \mu \mathrm{g} / \mathrm{mL})$ direnç göstermektedir [6, 7].

Heterojen direnç gösteren MRSA suşları, $\mathrm{NaCl}$ veya sukrozlu besiyeri kullanılması, düşük derecede inkübasyon gibi bazı özel kültür koşullarının sağlanmas1 durumunda homojen direnç gösterir hale gelmektedir. Değişik kültür koşullarına göre direncin ortaya konulmasında meydana gelen bu değişiklik geçicidir ve tamamen fenotipiktir [6]. Homojen direncin ortaya çıkmasını arttıran bazı koşulların bakteri otolizisindeki değişikliklerle ilişkili olduğu gözlemlenmiştir [5, 7, 23]. S. aureus suşlarında dirençten sorumlu geni taşımalarına rağmen heterojen direncin görülme nedeninin, mecA geninin fonksiyonunu kontrol ettiği düşünülen fem (factors essential for the expression of methicillin resistance) faktörü olarak tanımlanmış genlerden ileri geldiğ $i$ bilinmektedir. Heterojen direncin gelişiminde $\mathrm{fem}$ $A$ ve fem $X$ kontrol genlerinden bir veya birkaçının $m e c A$ geninin ekspresyonunu inhibe etmesine bağl1 olduğu düşünülmektedir [6, 23].

MRSA suşlarında olduğu gibi MSSA suşlarında da fem faktörleri bulunabilmektedir [4, 10, 19]. fem faktörünün yanı sira mecRl-mecI sistemi yer almaktadır. mecA geni, $m e c R l$ ve $m e c I$ olmak üzere iki regülatör gen ile kontrol edilmektedir. $m e c R l$ ve $m e c I$ genleri beta-laktamaz geninin regülatör genleri olan blaRl ve blaI ile yap1, fonksiyon ve regülasyon mekanizması açısından benzerlik göstermektedir [28]. BlaI, blaI geni tarafindan kodlanan, beta-laktamaz geninin transkripsiyonunu inhibe eden bir proteindir. BlaR1 ise blaRl geni tarafindan kodlanır ve beta-laktamaz varlığında beta-laktamaz gen transkripsiyonunu sağlar. mecI ve mecRl, mec $A$ için aynı düzenleyici rolü oynar. $m e c I, m e c A$ 'yı bask1layan bir protein, $m e c R 1$ ise sinyal uyarıc1 bir protein kodlar [27, 28].

Fenotipik direnci ortaya çıkaran diğer durum ise beta-laktamaz plazmidi olarak bilinmektedir. Beta-laktamaz enzim yapımı blaZ geni tarafindan kodlanır. Antirepresör olan blaRl ve represör olan blaI olmak üzere iki gen tarafindan kontrol edilir. Ortamdaki beta-laktam, BlaRl'e (transmembran proteini) bağlanır ve bakterinin dışından içine sinyal iletimini sağlayarak beta-laktamaz enziminin sentezinin başlamasında rol oynar. Böylece metisilin direncinin fenotipik olarak ortaya konmasinda etkili bir rol üstlenmiş olur [38].

MRSA'ların çoğunda beta-laktamaz genini taŞ1yan plazmid bulunması ve mecRl-mecI sisteminin defektif olması nedeniyle mec $A$ geninin esas olarak "bla sistemi" ile indüklendiği düşünülmektedir [6, 7]. Beta-laktam grubunda yer alan bir antibiyotik ile indüksiyon yapıldığında, blaRl-blaI sisteminde meydana gelen indüklenme, mecRl-mecI sisteminden daha hizlı olmaktadır. Aynı zamanda mecR 1-me$c I$ sistemi ile kıyaslama yapıldığında, mecA geninin baskılanması, blaR1-blaI sistemine göre daha zayıf olmaktadir [17].

MRSA'larda mecC geninin varlığ 1 ilk olarak 2007 yılında Güneybatı İngiltere'de sığır mastitisinin epidemiyolojik bir çalışması sırasında tank sütü örneklerinden MRSA izolasyonu ile saptanmıştır [12]. LGA251 olarak adlandırılan MRSA suşunun $m e c A$ geni ve PBP2/2a için doğrulayıcı testlerde tamamı negatif olarak belirlenmiştir. "Wellcome Trust Sanger Institute", LGA251 suşunun , başlangıçta mecALGA251 olarak adlandırdığ1 yeni bir mecA geni homoloğu taşıdığını ortaya koşmuştur [13]. LGA251 suşunun DNA's1 mecA genine \%69 ve PBP'lerin amino asit kompozisyonuna $\% 63$ oranında özdeşleştiği saptanmıştır. LGA251 suşundan alınan SCCmec dizisi "Working Group on the Classification of SCC" tarafindan değerlendirilerek Kasim 2009 yılında Tip XI SCCmec geninin varlığını bildirmiştir ve mecALGA251 olarak adlandırılan gen, 2012 yılında mecC olarak yeniden adlandırılmıştır [21, 22]. mecC geni tarafindan kodlanmış PBP'lerin işlevi, $\beta$-laktam direncinin rolü ve dikkate değer farklılıkları, yapılan çalışmalar ile bildi- 
rilmiştir. mecC tarafından kodlanan PBP'ler, $\beta$-laktam'a karşı yüksek affinite gösterirken, mecA geni tarafindan kodlanan PBP'ler daha az affinite göstermiştir [26]. Termostabilite ve sicaklık değerlerindeki aktivasyonu ile ilgili değerlendirmelerde ise $m e c C$ geni tarafindan kodlanan PBP'ler, $m e c A$ geni tarafindan kodlanan PBP'lerden daha kararsız yap1ya sahip olduğu bildirilmiştir[26]. Bu karakterizasyonlar, MRSA'nın PBP2 fonksiyonunu ve metisilin direncindeki rolünü teyit etmektedir. $m e c A$ ve $m e c C$ genleri tarafindan kodlanan proteinlerin davranışlarında önemli farklılıklar vardır. Bu moleküllerin ayrımında yapısal ve evrimsel temeller henüz tam olarak belirlenememiştir ve bu konuda araştırmalar devam etmektedir [44].

\section{Sonuç ve Öneriler}

MRSA prevalansı ülkemizde ve dünyada hızla artmaktadır. Prevalans ülkeler arasında, hastaneler ve hastanelerin farklı üniteleri arasında da değişik oranlar göstermektedir. MRSA çoklu ilaç direnci göstermesi nedeniyle günümüzde kullanılabilecek antibiyotik seçeneklerini oldukça kısıtlamaktadır. Tek başına bir antibiyotik yeterli olmamakta ve mutlaka kombine antibiyotik tedavisi uygulanmalıdır. Bu kapsamda kullanılabilecek antibiyotikler; vankomisin, linezolid, kinupristin, dalfopristin, daptomisin daha çok tercih edilmekte ve kombine şekilde kullanılmaktadır [8, 42, 43].

Hekimliğimizde hayvan türleri arasında gözlemlenen MRSA prevalans artışının temelinde bilinçsiz ve akılcı olmayan antibiyotik kullanımı söz konusudur [11]. Veteriner Hekimlik alanında antibiyotik kullanımı öncesi en kolay ve ekonomik metot olan antibiyogram uygulamasinin yapilmasi ve doğru antibiyotiklerin tercih edilmesi gerekmektedir. Bu doğrultuda Veteriner Hekim kontrolünde antibiyotik kullanımı ile ilgili sıkı önlemler alınmalı, hayvanlarda kullanılan antibiyotiklerin türü, miktarı ve bu antibiyotiklere karşı oluşan direnç izlenmeli, uygun süre ve dozlarda kullanımına dikkat edilmeli, kontrolsüz ve aşırı ilaç kullanımından kaçınılmal1dir.

\section{Kaynaklar}

1. Appelbaum PC (2006). MRSA the tip of the iceberg. Clin Microbiol Infect. 12(2):3-10.
2. Appelbaum PC (2007). Microbiology of antibiotic resistance in Staphylococcus aureus. Clin Infect Dis. (45):6570.

3. Baptiste KE, Williams K, Williams NJ, Wattret A, Clegg PD, Dawson S, Corkill JE, O’Neill T, Hart CA (2005). Methicillin-resistant Staphylococci in Companion Animals. Emerg. Infect. Dis. (11):1942-1944.

4. Berger-Baechi B (1989). Genetics of methicillin resistance in Staphylococcus aureus. J Antimicrob Chemother. (23):671-675.

5. Chambers HF (1988). Methicillin-resistant staphylococci. Clin Microbiol Rev. (1):173-186.

6. Chambers HF (1997). Methicillin resistance in staphylococci: molecular and biochemical basis and clinical implications. Clin Microbiol Rev. (10):781-791.

7. Chambers HF, Hackbarth CJ (1987). Effect of $\mathrm{NaCl}$ and nafcillin on penicillin-binding protein $2 \mathrm{a}$ and heterogeneous expression of methicillin resistance in Staphylococcus aureus. Antimicrob Agents Chemother. (31):1982-1988.

8. Chambers HF (2001). The changing epidemiology of Staphylococcus aureus Emerg. Infect. Dis. (7):178-182.

9. Demirel G, Findık D, Dagi HT, Arslan U (2014). Community-Acquired Methicillin-Resistant Staphylococcus aureus and Genotypes Amoung University Students in TURKEY. Southeast Asian J Trop Med Public Health. 45(6):1401-1409.

10. Eliopoulos G (2005). Antimicrobial agents for treatment of serious infections caused by resistant $S$. aureus and enterococci. Eur J Clin Microbiol Infect Dis. 24(12):826831.

11. Enright MC, Robinson DA, Randle G, Feil EJ, Grundmann H, Spratt BG (2002). The evolutionary history of methicillin-resistant Staphylococcus aureus (MRSA). Proc. Natl. Acad. Sci. USA. 99(11):7687-7692.

12. Álvarez L, Webb C, Holmes M (2011). A novel fieldbased approach to validate the use of network models for disease spread between dairy herds. Epidemiol Infect. 139(12):1863-1874.

13. Álvarez L, Holden M, Lindsay H, Webb C, Brown D, Curran M, Walpole E, Brooks K, Pickard DJ, Teale C, Parkhill J,Bentley SD, Edwards GF, Girvan EK, Kearns AM, Pichon B, Hill LRL, Larsen AR, Skov RL, Peacock SJ, Maskell DJ, Holmes M (2011). Meticillin-resistant Staphylococcus aureus with a novel mecA homologue in human and bovine populations in the UK and Denmark: a descriptive study. The Lancet. 11(8):595-603.

14. Gordon RJ, Lowy FD (2008). Pathogenesis of methicillinresistant Staphylococcus aureus infection. Clin. Infect. Dis. (46):350-359.

15. Grundmann H, Aires-de-Sousa M, Boyce J, Tiemersma E (2006). Emergence and resurgence of meticillin-resistant S. aureus as a publichealth threat. The Lancet. (368):874 885.

16. Hackbarth CJ, Chambers HF (1993). blaI and blaRl regulate $\beta$-lactamase and $P B P 2 a$ production in methi- 
cillin resistant S. aureus. Antimicrob Agents Chemother. (39):1144-1149.

17. Hackbarth CJ, Miick C, Chambers HF (1994). Altered production of penicillin-binding protein $2 \mathrm{a}$ can affect phenotypic expression of methicillin resistance in Staphylococcus aureus. Antimicrob Agents Chemother. (38):2568-2571.

18. Hartman BJ, Tomasz A (1986). Expression of methicillin resistance in heterogeneous strains of Staphylococcus aureus. Antimicrob Agents and Chemother. (29):85-92.

19. Henze U, Sidow T, Wecke J, Labischinski H, Berger-Bachi $B$ (1993). Influence of femB on methicillin resistance and peptidoglycan metabolism in S.aureus. J Bacteriol. (175):1612-1620.

20. Hiramatsu K, Katayama Y, Yuzawa H, Ito T (2002). Molecular genetics of methicillin-resistant Staphylococcus aureus. Int. J. Med. Microbiol. (292):67-74.

21. International Working Group on the Classification of Staphylococcal Cassette Chromosome Elements (IWG-SCC) (2009). Classification of Staphylococcal Cassette Chromosome mec (SCCmec): Guidelines for Reporting Novel SCCmec Elements. Antimicrob Agents Chemother. 53(12):4961-4967.

22. Ito $\mathrm{T}$, International Working Group on the Classification of Staphylococcal Cassette Chromosome Elements (IWGSCC) (2012). Guidelines for reporting novel mecA gene homologues. Antimicrob. Agents Chemother. (56):49974999.

23. Jacoby GA, Archer GL (1991). New mechanisms of bacterial resistance to antimicrobial agents. N. Eng. J. Med. (324): 601-612.

24. Jevons MP (1961). Celbenin resistant Staphylococci. BMJ. (1):124-125.

25. Jonge BL, Tomasz A (1993). Abnormal peptidoglycan produced in a methicillin-resistant strain of $S$. aureus grown in the presence of methicillin: functional role for penicillin-binding protein 2A in cell wall synthesis. Antimicrob. Agents Chemother. (37):342-346.

26. Kim C, Milheiriço C, Gardete S, Holmes MA, Holden MTG, de Lencastre H, Tomasz A (2012). Properties of a Novel PBP2A Protein Homolog from Staphylococcus aureus Strain LGA251 and Its Contribution to the $\beta$-Lactamresistant Phenotype. J Biol Chem. 287(44): 36854-36863.

27. Kobayashi N, Taniguchi K, Urasawa S (1998). Analysis of diversity of mutations in the mecI gene and mecA promoter/operator region of methicillin-resistant Staphylococcus aureus and Staphylococcus epidermidis. Antimicrob Agents Chemother. (42):717-720.

28. Kuwahara-Arai K, Kondo N, Hori S, Tateda-suzuki E, Hiramatsu K (1996). Suppression of methicillin resistance in a mecA containing pre-methicilin-resistant $S$. aureus strain is caused by the mecI mediated repression of PBP2' production. Antimicrob Agents Chemother. (40):26802685.

29. Liu GY (2009). Molecular pathogenesis of $S$. aureus infection. Pediatr. Res. (65):71-77.
30. Lowy FD (1998). Staphylococcus aureus infections. New. Eng. J. Med. (20):520-531.

31. Lozano C, López M, Gómez-Sanz E, Ruiz-Larrea F, Torres C, Zarazaga M (2009). Detection of methicillinresistant Staphylococcus aureus ST398 in food samples of animal origin in Spain. J. Antimicrob. Chemother. (64):1325-1326.

32. Monecke S, Aamot HV, Stieber B, Ruppelt A, Ehricht R (2014). Characterization of PVL-positive MRSA from Norway. APMIS. 122(7):580-584.

33. Morgan M (2008). Methicillin-resistant Staphylococcus aureus and animals: zoonosis or humanosis. J. Antimicrob. Chemother. (62):1181-1187.

34. Ogston A (1881). Report upon microorganisms in surgical diseases. J Br Med.(1):369-375.

35. Özgünes N, Ergen P, Ceylan N, Yazıcı S, Aksoy Y (2002). Yatan hastalardan ve poliklinik hastalarından izole edilen stafilokok suşlarında metisilin direnci ve dirençli suşlarda glikopeptid duyarlılığı. ANKEM Derg. (16):423-426.

36. Peacock S (2006). Staphylococcus aureus. Principles and practice of clinical bacteriology. (2):73-98.

37. $\mathrm{Pu} \mathrm{S}, \mathrm{Han} \mathrm{F}, \mathrm{Ge} \mathrm{B}$ (2009). Isolation and characterization of methicillin resistant $S$. aureus strains from Louisiana retail meats. Appl. Environ.Microbiol. (75):265-267.

38. Ryffel C, Kayser FH, Berger-Bachi B (1992). Correlation between regulation of mecA transcription and expression of methicillin-resistance in staphylococci. Antimicrob Agents Chemother. (36):25-31.

39. Shore AC, Deasy EC, Slickers P, Brennan G, O'Connell B, Monecke S, Coleman DC (2011). Detection of Staphylococcal Cassette Chromosome mec Type XI Carrying Highly Divergent mecA, mecI, mecRl, bla $Z$, and $c c r$ Genes in Human Clinical Isolates of Clonal Complex 130 Methicillin Resistant Staphylococcus aureus. Antimicrob Agents Chemother. 55(8):3765-3773.

40. Shorr AF (2007). Epidemiology of staphylococ resistance. Clin. Infect. Dis. (45):171-176.

41. Stefani S, Goglio A (2010). Methicillin-resistant Staphylococcus aureus: related infections and antibiotic resistance. Int J Infect Dis. 14(4):19-22.

42. Stefani S, Varaldo PE (2003). Epidemiology of methicillin-resistant staphylococci in Europe. Clin. Microbiol. Infect. (9):1179-1186.

43. Tsiodras S, Gold HS, Sakoulas G (2001). Linezolid resistance in a clinical isolate of Staphylococcus aureus. The Lancet. 358(9277):207-208.

44. Tsubakishita S, Kuwahara-Arai K, Baba T, Hiramatsu K (2010). Staphylococcal Cassette Chromosome mec-Like Element in Macrococcus caseolyticus . Antimicrobial Agents and Chemotherapy. 54(4):1469-1475.

45. Zetola N, Francis JS, Nuermberger EL, Bishal WR (2005). Community acquired meticillin-resistant Staphylococcus aureus: an emerging threat. The Lancet Infect. Dis. (5):275-286. 